\title{
Desempenho agronômico do milho sob adubação mineral e inoculação das sementes com rizobactérias
}

\author{
Mariana A. de Oliveira ${ }^{1}$, Claudemir Zucareli ${ }^{2}$, Leandro T. Spolaor ${ }^{3}$, \\ Allan R. Domingues ${ }^{3}$ \& André S. Ferreira ${ }^{3}$
}

\begin{abstract}
RESU M O
Para avaliar o desempenho agronômico da cultura do milho (Zea mays) de segunda safra submetido à inoculação com Pseudomonas fluorescens sob níveis de adubação N PK, um experimento em campo foi conduzido utilizando-se a cultivar de milho híbrido 30 F35 cultivada em Latossolo Vermelho eutroférrico. Foram testados seis tratamentos sob o delineamento experimental de blocos casualizados, em esquema fatorial $3 \times 2$, sendo três níveis de adubação química com NPK $\left(0,125\right.$ e $\left.250 \mathrm{~kg} \mathrm{ha}^{-1}\right)$ e dois níveis de inoculante à base de P. fluorescens (com e sem), com quatro repetições. Foram avaliados as características fitométricas, os componentes de produção e a produtividade de grãos do milho. Os dados foram submetidos à análise de variância e as médias comparadas pelo teste de Tukey $p<0,05$. A inoculação com Pseudomonas fluorescens associada à adubação de semeadura com $250 \mathrm{~kg} \mathrm{ha}^{-1}$ de N PK, favorece o desenvolvimento e o desempenho produtivo do milho de segunda safra.
\end{abstract}

Palavras-chave: Zea mays, Pseudomonas fluorescens, componentes de produção, produtividade

\section{Agronomic performance of maize under mineral fertilizer and seed inoculation with rhizobacteria}

\begin{abstract}
To evaluate the agronomic performance of second maize (Zea mays) crop, subjected to inoculation with Pseudomonas fluorescens under different levels of NPK fertilization, a field experiment was conducted using the cultivar of hybrid maize $30 \mathrm{~F} 35$ grown in Oxisol. Six treatments were tested in a randomized block design in factorial scheme $3 \times 2$, with three levels of N PK $\left(0,125\right.$ and $\left.250 \mathrm{~kg} \mathrm{ha}^{-1}\right)$ and two levels of inoculants (with and without), and four replications. The characteristics, yield components and productivity were evaluated. The data were submitted to analysis of variance and means compared by Tukey test at $p<0.05$ level. The inoculation with Pseudomonas fluorescens associated with fertilization with 250 $\mathrm{kg} \mathrm{ha}^{-1} \mathrm{NPK}$ at sowing time promotes the development and productive performance of second maize crop.
\end{abstract}

Key words: Zea mays, Pseudomonas fluorescens, production components, productivity

D outoranda em Agronomia, UEL. E-mail: agro-star@hotmail.com

Departamento de Agronomia, UEL. Rodovia Celso Garcia Cid, Cx. P. 6001, CEP: 86051-990, Londrina, PR. Fone: (44) 3371-5985. E-mail: claudemircca@uel.br

Graduando em Agronomia, UEL.E-mail: leandrotspolaor@hotmail.com; allandomingez@hotmail.com; asampaio_5@hotmail.com 


\section{INTRODUÇÃO}

Com a necessidade de um aumento de produtividade agrícola no País, torna-se primordial o avanço científico nos estudos do suprimento das carências nutricionais das diversas culturas, tal como o conhecimento das limitações nutricionais cada vez mais como fator de relevância para a ciência e para a agricultura.

Diversos trabalhos demonstram o efeito positivo da adubação NPK nos componentes de produção para a cultura do milho, com benefícios sobre características agronômicas, como diâmetro caulinar, número de grãos/espiga, peso da espiga com e sem palha, rendimento de grãos pela cultura e, ainda, aumento na produção de massa de matéria seca da parte aérea (Aratani et al., 2006; Harger et al., 2007; Gonçalves Júnior et al., 2007; 2008; Deparis et al., 2007).

O uso crescente de fertilizantes para corrigir o problema da baixa disponibilidade de fósforo exerce forte impacto econômico e ambiental, visto que os processos químicos para a produção desses fertilizantes são de custo elevado, em termos energéticos, além de utilizarem fontes não-renováveis e finitas de energia (Oliveira Júnior et al., 2008). De acordo com Richardson (2000), os solos tropicais são, na sua maioria, pobres em fósforo disponível às plantas enquanto o fertilizante fosfatado representa alto custo para o agricultor; desta forma, é interessante que se utilizem dos microorganismos do solo como inoculantes para mobilizar o fósforo em solos pobres.

Com o intuito de aumentar a eficiência na utilização de fertilizantes nos sistemas agrícolas mantendo o equilíbrio ecológico aumentou-se, recentemente, o interesse pela manipulação de rizobactérias promotoras do crescimento de planta (RPCPs), que apresentam grande potencialidade e praticabilidade de uso. Essas bactérias exercem efeitos benéficos ao promover o crescimento vegetal cuja ocorrência é devida ao aumento da disponibilidade de nutrientes para as plantas, seja pela solubilização de fosfato inorgânico (Rodríguez \& Fraga, 1999; Zaidi \& Mohammad, 2006) ou pelo maior crescimento das raízes, favorecendo a absorção de água e nutrientes.

Existem relatos de promoção de crescimento por rizobactérias em culturas como milho (Cardoso et al., 2008; Naveed et al.,
2008), trigo (Sheng \& He, 2006; Rana et al., 2012), entre outras. A promoção de crescimento leva ao aumento na produção de grãos e ao crescimento da planta, que podem ser expressos tanto pela massa da matéria seca da parte aérea ou raízes, como pela altura (Coelho et al., 2007).

As Pseudomonas surgem como alternativa de relevante importância no suprimento de nutrientes necessários às culturas, favorecendo o aumento da absorção de fósforo pelas plantas (Lifishitz et al., 1987; Afzal \& Bano, 2008), com a tentativa de reduzir o custo com a adubação mineral e os riscos ambientais causados pela utilização inadequada, excessiva ou até mesmo incipiente, de adubos químicos, beneficiando a produção agrícola e diminuindo os custos para o produtor (Coelho et al., 2007).

Por se tratar de micro-organismos, as rizobactérias podem apresentar alterações de comportamento em virtude das mudanças climáticas e dos níveis de nutrientes do solo, o que pode levar ao insucesso da interação bactéria-planta não proporcionando, assim, os benefícios esperados. As condições climáticas e de solo podem influenciar a estabilidade, a sobrevivência e até mesmo a atuação das rizobactérias.

Visando ao entendimento das relações bactéria-planta realizou-se o trabalho com o objetivo de avaliar o desempenho agronômico da cultura do milho de segunda safra, submetida à inoculação de Pseudomonas fluorescens e cultivado sob diferentes níveis de adubação NPK.

\section{Material e MÉTODOS}

O trabalho foi realizado em condições de campo no município de Londrina, PR, onde se encontra a $23^{\circ} 22^{\prime}$ latitude Sul, $51^{\circ} 22^{\prime}$ longitude Oeste, com $580 \mathrm{~m}$ de altitude. O clima característico da região, segundo a classificação de Köppen, é do tipo CFA, ou seja, clima subtropical úmido mesotérmico, com verões quentes e geadas pouco frequentes. Os dados metereológicos do período de condução do experimento foram obtidos junto à estação Metereológica do Instituto Agronômico do Paraná, situada a $5 \mathrm{~km}$ da área experimental, estando dispostos na Figura 1.

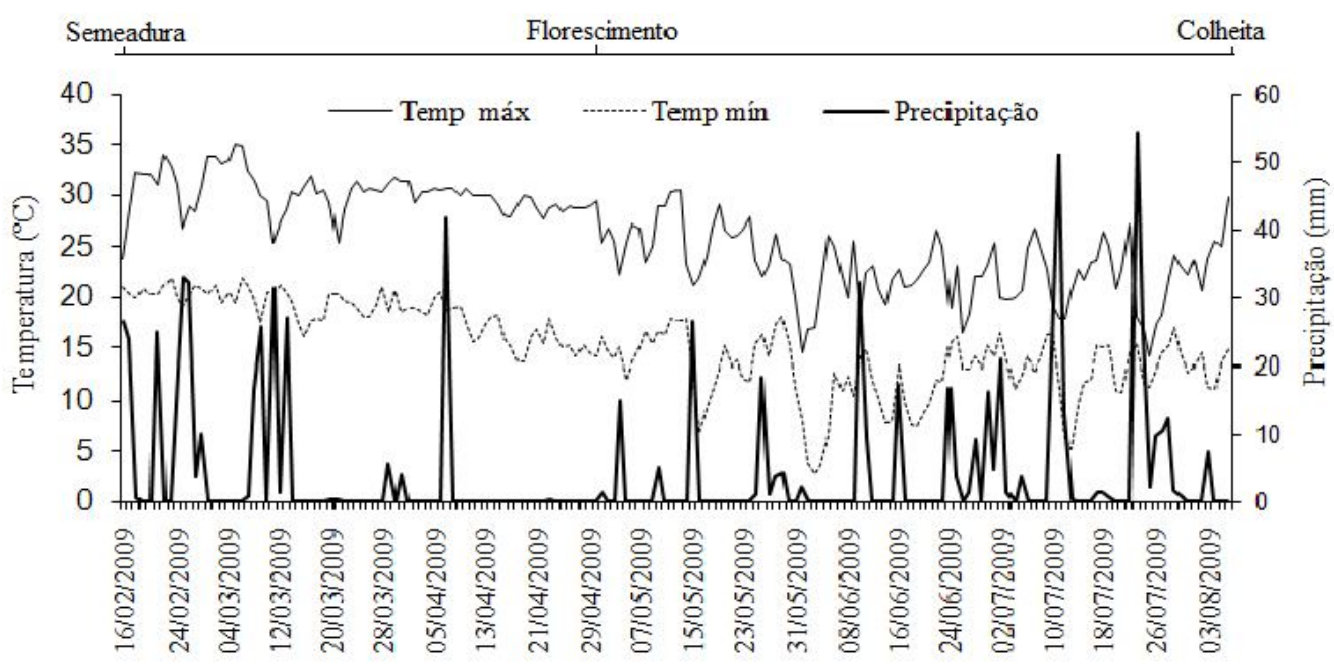

Figura 1. Dados diários de temperaturas máximas e míninas e de precipitação pluvial durante o período de condução do experimento 
O experimento foi instalado no dia 18 de fevereiro de 2009, utilizando-se a cultivar de milho híbrido 30F35 da Pioneer, que apresenta ciclo precoce, alto potencial produtivo e elevada capacidade de adaptação para a safrinha.

O experimento foi instalado em solo classificado como Latossolo Vermelho eutroférrico (EMBRAPA, 1999). Previamente a instalação do experimento foram coletadas amostras de solo da área experimental a profundidade de 0-10 e 10-20 cm para análise química de acordo com a metodologia de Raij \& Quaggio (1983). O solo foi preparado ao apresentar condições adequadas de umidade, procedendo-se a uma aração na profundidade de $20 \mathrm{~cm}$ e a uma gradagem para nivelamento.

Testaram-se seis tratamentos utilizando-se o delineamento experimental de blocos casualizados, em esquema fatorial $3 \times 2$, correspondente a três níveis de adubação NPK, sendo uma testemunha sem adubação e duas quantidades do fertilizante 08-28-16, sendo 125 e $250 \mathrm{~kg} \mathrm{ha}^{-1}$, combinados com dois níveis de inoculante (com e sem), com 4 repetições. As adubações de NPK foram calculadas com base nos resultados da análise química do solo (Tabela 1) e nas recomendações para a região (EMBRAPA, 2009), sendo a dose de $250 \mathrm{~kg} \mathrm{ha}^{-1}$ correspondente a $100 \%$ da recomendação.

As sementes foram tratadas momentos antes da semeadura com o inoculante à base de Pseudomonas fluorescens, Rizofos $^{\circledR}$, utilizando-se $140 \mathrm{~mL} \mathrm{ha}{ }^{-1}$, correspondentes a $100 \mathrm{~mL}$ de Rizofos ${ }^{\circledR}$ e $40 \mathrm{~mL}$ de Premax-R ${ }^{\circledR}$ (protetor bacteriano que melhora a sobrevivência das bactérias após a inoculação). A inoculação consistiu em se colocar as sementes e o produto em saco plástico, com posterior agitação para distribuição homogênea do inoculante sobre as sementes.

As parcelas foram constituídas de quatro linhas de cinco metros de comprimento, com espaçamento entre linhas de 0,9 m. Consideraram-se, como parcelas úteis, as duas linhas centrais, desprezando-se $0,5 \mathrm{~m}$ das suas extremidades. A semeadura foi realizada manualmente, no sistema convencional de cultivo. Para atingir a densidade de aproximadamente 55.000 plantas ha-1 realizou-se o desbaste na fase de desenvolvimento $\mathrm{V}_{3}$, utilizando-se a escala fenológica da cultura, proposta por Ritchie et al. (1986).

Durante o desenvolvimento da cultura a área experimental foi monitorada quanto às pragas, doenças e plantas daninhas. Houve a necessidade de controle de vaquinha (Diabrotica speciosa) devido à desfolha causada pelo inseto adulto no estádio V3 da cultura. Utilizou-se Teflubenzuron na dosagem de $100 \mathrm{~mL} \mathrm{ha}^{-1}$; a eliminação de plantas daninhas foi realizada mediante capina manual.

A adubação nitrogenada de cobertura foi realizada aos 35 dias após a emergência das plântulas (estádio $\mathrm{V}_{6}$ ), com aplicação de $80 \mathrm{~kg} \mathrm{ha}^{-1}$ de N (ureia, para todos os tratamentos); já a colheita foi realizada manualmente, quando os grãos apresentavam teor de água médio de $20 \%$, na área útil da parcela.
Foram avaliados as características fitométricas, os componentes de produção e a produtividade. As características fitométricas avaliadas foram: Altura da planta: obtida com o auxílio de uma régua, cujas medidas foram realizadas em seis plantas tomadas de forma aleatória da área útil de cada parcela experimental; considerando-se a distância do colo da planta até a inserção da folha-bandeira, o resultado em $\mathrm{cm}$ foi dado pela média das plantas avaliadas; Altura da inserção da espiga: determinada no final do ciclo da cultura avaliando-se seis plantas tomadas ao acaso das duas linhas centrais da área útil de cada parcela, medindo-se o comprimento $(\mathrm{cm})$ da base da planta até a inserção da primeira espiga obtendo-se, então, o valor médio em $\mathrm{cm}$; Stand final: contabilizou-se a população final da área útil da parcela e se realizou o ajuste para plantas ha ${ }^{-1}$.

Para avaliação dos componentes de produção foram coletadas 10 espigas, ao acaso, das linhas centrais da parcela, visando às seguintes determinações: Peso de espiga: as 10 espigas foram pesadas para se obter o peso médio de uma espiga em gramas; Comprimento da espiga: com as espigas já desempalhadas foi medida a distância entre o primeiro e oúltimo grão da linha mais longa obtendo-se, assim, o valor médio do comprimento da espiga em centímetros; Número de fileiras por espiga e grãos por fileira: foi contado individualmente, em cada uma das 10 espigas, o número de fileiras de grãos. Para o número de grãos por fileiras foi contado o número de grãos da fileira mais longa. Em ambas as avaliações se obteve o valor médio das espigas avaliadas; Diâmetro da espiga e do sabugo: o diâmetro da espiga foi obtido na região mediana da espiga com auxílio de um paquímetro manual. Após a debulha das espigas foi medido o diâmetro do sabugo na sua região mediana; Índice de espiga: foi obtido pela divisão do número de espigas pelo número de plantas da área útil da parcela experimental; Massa de 100 grãos: após a debulha das espigas de cada parcela útil, foi realizada a homogeneização do lote e, posteriormente, foram separadas duas repetições de 100 grãos, os quais foram pesados em uma balança digital obtendo-se a massa de 100 grãos por meio da média das duas pesagens.

O teor de água dos grãos após a colheita foi obtido por um medidor de capacitância digital (G600), previamente ajustado e calibrado para a cultura do milho. A produtividade de grãos foi obtida por meio da pesagem dos grãos colhidos na área útil da parcela experimental, com umidade corrigida para $13,0 \%$ (umidade de armazenamento para grãos de milho) e ajuste dos dados para $\mathrm{kg} \mathrm{ha}^{-1}$. Os dados foram submetidos à análise de variância e as médias comparadas pelo teste de Tukey $\mathrm{p}<0,05$.

\section{RESULTADOS E DISCUSSÃO}

Constatou-se alteração significativa na altura de planta e na altura de inserção de espiga com a inoculação de rizobactérias

Tabela 1. Caracterização química do solo da área experimental na profundidade de 0-10 e 10-20 cm

\begin{tabular}{|c|c|c|c|c|c|c|c|c|c|c|c|c|c|c|}
\hline \multirow{2}{*}{$\begin{array}{l}\text { Prof. } \\
(\mathrm{cm})\end{array}$} & \multicolumn{2}{|c|}{$\mathrm{pH}$} & $\mathrm{H}+\mathrm{Al}$ & $\mathrm{Ca}^{2+}$ & $\mathrm{Mg}^{2+}$ & $\mathrm{K}^{+}$ & CTC & \multirow{2}{*}{$\begin{array}{l}\mathbf{V} \\
\%\end{array}$} & $\mathbf{P}$ & $M n$ & $\mathrm{Fe}$ & $\mathrm{Cu}$ & $\mathrm{Zn}$ & B \\
\hline & $\mathrm{CaCl}_{2}$ & $\mathrm{H}_{2} \mathrm{O}$ & & & $\mathrm{nol}_{\mathrm{c}} \mathrm{dn}$ & & & & \multicolumn{6}{|c|}{$\mathrm{mg} \mathrm{dm}^{-3}$} \\
\hline $0-10$ & 5,3 & 6,0 & 4,2 & 5,7 & 1,5 & 0,9 & 12,3 & 66,27 & 10,51 & 224,2 & 64,99 & 17,40 & 12,26 & 0,66 \\
\hline $10-20$ & 5,1 & 5,7 & 4,9 & 4,6 & 1,2 & 0,4 & 11,1 & 55,53 & 6,46 & 214,5 & 73,69 & 17,22 & 2,92 & 0,84 \\
\hline
\end{tabular}


e apenas de adubação para a altura de planta (Tabela 2). A interação entre os fatores adubação e inoculação também foi significativa para ambas as características. Os diferentes níveis de adubação, de inoculação e a interação entre esses fatores não influenciaram significativamente a variável stand final.

Tabela 2. Médias da altura de planta (AP), altura da inserção da espiga (AE) e stand final (SF) de plantas de milho, submetidas a diferentes doses de adubação NPK e inoculação das sementes com Pseudomonas fluorescens

\begin{tabular}{lccc}
\hline \multirow{2}{*}{ Causas de variação } & \multicolumn{3}{c}{ Variáveis analisadas } \\
\cline { 2 - 4 } & AP (cm) & AE (cm) & SF \\
Adubação $\left(\mathrm{kg} \mathrm{ha}^{-1}\right)$ & & & \\
0 & 1,88 & 1,05 & 47360,50 \\
125 & 1,82 & 1,07 & 46804,75 \\
250 & 1,90 & 1,06 & 50554,75 \\
\hline Inoculação & & & \\
Sem & 1,90 & 1,10 & 48332,58 \\
Com & 1,83 & 1,02 & 48147,41 \\
\hline Valor de F & & & \\
Adubação (A) & $8,83^{*}$ & $0,21 \mathrm{~ns}$ & $1,70 \mathrm{~ns}$ \\
Inoculação (I) & $20,60 *$ & $9,40 *$ & $0,01 \mathrm{~ns}$ \\
A * I & $14,81^{*}$ & $5,77 *$ & $0,40 \mathrm{~ns}$ \\
\hline CV (\%) & 2,12 & 5,91 & 9,11 \\
\hline
\end{tabular}

ns não-significativo, * significativo a 0,05 de probabilidade

O stand médio final foi de 48.240 plantas ha $^{-1}$, mostrando-se adequado para o período de cultivo de segunda safra onde, para híbridos, varim de 45 a 55 mil plantas ha- ${ }^{-1}$. De acordo com Almeida et al. (2000) o manejo da densidade de plantas é uma das práticas culturais mais relevantes para determinar o rendimento de grãos no milho. As respostas à densidade de plantas incluem mudanças na arquitetura da comunidade de plantas, no crescimento, no desenvolvimento e na absorção e partição de assimilados pelas plantas.

Na Tabela 3 são apresentados os desdobramentos da interação dos fatores estudados (adubação e inoculação) para altura de planta e altura de inserção de espiga.

Tabela 3. D esdobramento da interação para médias de altura total e altura de inserção de espiga das plantas de milho, em função de diferentes doses de adubação N PK e inoculação das sementes com Pseudomonas fluorescens

\begin{tabular}{|c|c|c|c|c|}
\hline \multirow{2}{*}{$\begin{array}{l}\text { Adubação } \\
\left(\mathrm{kg} \mathrm{ha}^{-1}\right)\end{array}$} & \multicolumn{2}{|c|}{ Altura de planta $(\mathrm{cm})$} & \multicolumn{2}{|c|}{ Altura de espiga $(\mathrm{cm})$} \\
\hline & SI & $\mathrm{Cl}$ & SI & $\mathrm{Cl}$ \\
\hline 0 & $1,89 \mathrm{Aa}$ & $1,87 \mathrm{Aa}$ & $1,03 \mathrm{Ba}$ & $1,06 \mathrm{Aa}$ \\
\hline 125 & $1,92 \mathrm{Aa}$ & $1,72 \mathrm{Bb}$ & $1,16 \mathrm{Aa}$ & $0,97 \mathrm{Ab}$ \\
\hline 250 & $1,90 \mathrm{Aa}$ & $1,89 \mathrm{Aa}$ & $1,10 \mathrm{Aba}$ & $1,03 \mathrm{Aa}$ \\
\hline
\end{tabular}

Médias seguidas de mesma letra maiúscula na coluna para efeito de adubação e minúsculas na linha para efeito de inoculação, não diferem entre si pelo teste de Tukey a 0,05 de probabilidade $\mathrm{SI}$ - sem inoculação, $\mathrm{Cl}$ - com inoculação

$\mathrm{Na}$ ausência de inoculação com $P$. fluorescens não se constatou diferença significativa entre os níveis de adubações para altura de plantas; já na presença de inoculação as doses de 0 e $250 \mathrm{~kg} \mathrm{ha}^{-1}$ de adubação promoveram maiores médias para altura de planta em relação à dose de $125 \mathrm{~kg} \mathrm{ha}^{-1}$. A testemunha sem adubação e a dose de $250 \mathrm{~kg} \mathrm{ha}^{-1}$ não sinalizaram incrementos na altura de planta para ausência nem para presença de inoculação, embora na dose de $125 \mathrm{~kg} \mathrm{ha}^{-1} \mathrm{a}$ ausência de inoculação tenha apresentado acréscimos na altura de planta. Cardoso et al. (2008) avaliaram o efeito da inoculação de rizobactérias do gênero Pseudomonas no crescimento e desenvolvimento de plantas de milho precoce cultivado em casa de vegetação, com solo não estéril, e constataram efeito positivo da inoculação para a característica altura de plantas, divergindo dos resultados obtidos neste estudo.

Para a variável altura de inserção de espiga na presença de inoculação, os níveis de adubação não diferiram entre si. Nos tratamentos sem inoculação a adubação de $125 \mathrm{~kg} \mathrm{ha}^{-1}$ foi superior à testemunha sem adubação. Na dose de $125 \mathrm{~kg} \mathrm{ha}^{-1} \mathrm{a}$ ausência de inoculação também foi superior ao tratamento inoculado, favorecendo o aumento da altura de inserção de espiga, o que demonstrou comportamento semelhante ao observado para altura de plantas. Zucareli et al. (2011) não detectaram, em estudo relativo à eficiência agronômica do inoculante à base de Pseudomonas fluorescens em plantas de milho conduzido a campo, alteração na altura de planta e altura de inserção de espiga, corroborando com os resultados obtidos no presente estudo. Foi baixa a dispersão amostral nos resultados de altura de planta e altura de inserção da espiga, ocorrendo alta homogeneidade com o coeficiente de variação de 2,12 e 5,91\% e com a média geral 1,86 e 1,06 m.

As variáveis: comprimento de espiga, número de grãos por fileira, diâmetro da espiga, massa de 100 grãos, peso de espiga e produtividade, foram afetadas pela interação significativa entre os fatores adubação e inoculação como se observa na Tabela 4.

Por outro lado, as variáveis número de fileiras de grãos por espiga, diâmetro do sabugo e índice de espiga, não foram afetadas pelo fator adubação, inoculação e interação entre eles. Resultados divergentes a este trabalho foram apresentados por Gonçalves Júnior et al. (2007) ao avaliarem os componentes de produção e a produtividade da cultura do milho em função da adubação, com diferentes doses de Zn e NPK, em que o número de grãos por espiga, a massa de 1000 grãos e a produtividade de grãos, foram influenciados de forma significativa por doses de NPK, com aumento relevante na massa de 1000 grãos e, consequentemente, na produtividade.

Na Tabela 5 se apresentam o desdobramento da interação (adubação e inoculação) para o comprimento de espiga e o número de grãos por fileira.

Na ausência de inoculação não houve diferença significativa entre a testemunha e os níveis de fertilizantes para comprimento de espiga; já na presença de inoculação os níveis de 125 e 250 $\mathrm{kg} \mathrm{ha}^{-1}$ de adubação promoveram maiores médias para comprimento de espiga em relação à testemunha sem adubação. Para efeito de inoculação na testemunha sem adubação, a ausência de inoculação mostrou-se superior à presença.

Para o número de grãos por fileira os níveis de 0,125 e 250 $\mathrm{kg} \mathrm{ha}^{-1}$ de adubação, tanto na presença quanto na ausência de inoculação, não diferiram entre si; na dose de $250 \mathrm{~kg} \mathrm{ha}^{-1} \mathrm{de}$ adubação a presença de inoculante favoreceu o acréscimo do número de grãos por fileira, em relação à ausência de inoculante cujos resultados corroboram com Andreotti et al. (2008) que avaliaram a eficiência agronômica do inoculante à base de Pseudomonas fluorescens aplicado via tratamento de sementes, 
Tabela 4. M édias de comprimento da espiga (CE), número de fileiras por espiga (N FE), número de grãos por fileira (N G F), diâmetro da espiga (DE), diâmetro do sabugo (DS), índice de espiga (ÍE), massa de 100 grãos (M 100G ), peso de espiga (PE) e produtividade (P) de milho submetido a diferentes doses de adubação N PK e inoculação das sementes com Pseudomonas fluorescens

\begin{tabular}{|c|c|c|c|c|c|c|c|c|c|}
\hline \multirow{2}{*}{ Causas de variação } & \multicolumn{9}{|c|}{ Variáveis analisadas } \\
\hline & CE $(\mathrm{cm})$ & NFE & NGF & $\mathrm{DE}(\mathrm{cm})$ & DS (cm) & ÍE & M100G (g) & PE (g) & $P\left(\mathrm{~kg} \mathrm{ha}^{-1}\right)$ \\
\hline \multicolumn{10}{|l|}{ Adubação (kg ha-1) } \\
\hline 0 & 9,22 & 16,30 & 26,34 & 4,64 & 3,17 & 0,93 & 29,25 & 137,18 & 2610,55 \\
\hline 125 & 11,31 & 16,40 & 26,95 & 4,64 & 3,06 & 0,95 & 29,62 & 138,10 & 2639,30 \\
\hline 250 & 11,34 & 16,65 & 26,35 & 4,62 & 3,11 & 0,97 & 30,62 & 140,82 & 2972,11 \\
\hline \multicolumn{10}{|l|}{ Inoculação } \\
\hline Sem & 10,41 & 16,42 & 25,62 & 4,56 & 3,11 & 0,96 & 30,67 & 132,35 & 2782,63 \\
\hline Com & 10,84 & 16,48 & 27,47 & 4,70 & 3,12 & 0,94 & 29,00 & 145,05 & 2698,67 \\
\hline \multicolumn{10}{|l|}{ Valor de F } \\
\hline Adubação (A) & $4,37 *$ & $0,81 \mathrm{~ns}$ & 0,17 ns & 0,06 ns & $0,44 \mathrm{~ns}$ & 0,57 ns & 1,20 ns & $0,10 \mathrm{~ns}$ & $1,37 \mathrm{~ns}$ \\
\hline Inoculação (I) & $0,44 \mathrm{~ns}$ & $0,08 \mathrm{~ns}$ & $3,54 \mathrm{~ns}$ & $5,24 *$ & $0,96 \mathrm{~ns}$ & $0,48 \mathrm{~ns}$ & $4,95 \mathrm{~ns}$ & $3,48 \mathrm{~ns}$ & $0,18 \mathrm{~ns}$ \\
\hline$A * 1$ & $3,64 *$ & $1,52 \mathrm{~ns}$ & $3,99 *$ & $8,01 *$ & $0,21 \mathrm{~ns}$ & $1,26 \mathrm{~ns}$ & $7,14 *$ & $6,06 *$ & $3,03 *$ \\
\hline CV (\%) & 15,48 & 3,44 & 9,04 & 3,1 & 7,70 & 7,13 & 6,15 & 12,03 & 17,68 \\
\hline
\end{tabular}

Tabela 5. D esdobramento da interação para médias de comprimento de espiga e número de grãos por fileira de plantas de milho, em função de diferentes doses de adubação N PK e inoculação das sementes com Pseudomonas fluorescens

\begin{tabular}{|c|c|c|c|c|}
\hline \multirow{2}{*}{$\begin{array}{l}\text { Adubação } \\
\left(\mathrm{kg} \mathrm{ha}^{-1}\right)\end{array}$} & \multicolumn{2}{|c|}{$\begin{array}{l}\text { Comprimento de espiga } \\
(\mathrm{cm})\end{array}$} & \multicolumn{2}{|c|}{$\begin{array}{l}\text { Número de grãos } \\
\text { por fileira }\end{array}$} \\
\hline & SI & $\mathrm{Cl}$ & SI & $\mathrm{Cl}$ \\
\hline $\begin{array}{r}0 \\
125 \\
250\end{array}$ & $\begin{array}{l}10,65 \mathrm{Aa} \\
11,30 \mathrm{Aa} \\
10,58 \mathrm{Aa}\end{array}$ & $\begin{array}{r}7,79 \mathrm{Bb} \\
11,32 \mathrm{Aa} \\
12,09 \mathrm{Aa}\end{array}$ & $\begin{array}{l}24,77 \mathrm{Aa} \\
27,95 \mathrm{Aa} \\
24,15 \mathrm{Ab}\end{array}$ & $\begin{array}{l}27,90 \mathrm{Aa} \\
25,95 \mathrm{Aa} \\
28,55 \mathrm{Aa}\end{array}$ \\
\hline
\end{tabular}

Médias seguidas de mesma letra maiúscula na coluna para efeito de adubação e minúsculas na linha para efeito de inoculação, não diferem entre si pelo teste de Tukey a 0,05 de probabilidade $\mathrm{SI}$ - sem inoculação; $\mathrm{Cl}$ - com inoculação

na disponibilidade de fósforo e na maximização da produtividade de milho safrinha e relataram que a inoculação das sementes com P. fluorescens aumentou o número de grãos por espiga e o número de grãos por fileira enquanto a adubação fosfatada na dose de $60 \mathrm{~kg} \mathrm{ha}^{-1} \mathrm{de}_{2} \mathrm{P}_{5}$ proporcionou aumento no comprimento da espiga.

Os desdobramentos da interação para diâmetro de espiga e peso da espiga estão apresentados na Tabela 6. Para o diâmetro de espiga, as doses de 0,125 e $250 \mathrm{~kg} \mathrm{ha}^{-1}$ de adubação não diferiram quando na presença do inoculante. A dose de 125 $\mathrm{kg} \mathrm{ha}^{-1}$ mostrou-se superior à dose de $250 \mathrm{~kg} \mathrm{ha}^{-1}$ na ausência de inoculante. Na testemunha e na dose de $125 \mathrm{~kg} \mathrm{ha}^{-1} \mathrm{de}$

Tabela 6. D esdobramento da interação para médias de diâmetro da espiga e peso da espiga de plantas de milho, em função de diferentes doses de adubação N PK e inoculação das sementes com Pseudomonas fluorescens

\begin{tabular}{cccccc}
\hline $\begin{array}{c}\text { Adubação } \\
\text { (kg ha-1 })\end{array}$ & \multicolumn{2}{c}{ Diâmetro da espiga (cm) } & & \multicolumn{2}{c}{ Peso da espiga (g) } \\
\cline { 2 - 3 } & $\mathbf{S I}$ & $\mathbf{C l}$ & & $\mathbf{S I}$ & $\mathbf{C l}$ \\
125 & $4,64 \mathrm{ABa}$ & $4,63 \mathrm{Aa}$ & & $126,70 \mathrm{Aa}$ & $149,50 \mathrm{ABa}$ \\
250 & $4,66 \mathrm{Aa}$ & $4,61 \mathrm{Aa}$ & & $147,20 \mathrm{Aa}$ & $127,10 \mathrm{Ba}$ \\
& $4,38 \mathrm{Bb}$ & $4,85 \mathrm{Aa}$ & & $123,10 \mathrm{Ab}$ & $158,50 \mathrm{Aa}$ \\
\hline
\end{tabular}

Médias seguidas de mesma letra maiúscula na coluna para efeito de adubação e minúsculas na linha para efeito de inoculação, não diferem entre si pelo teste de Tukey a 0,05 de probabilidade $\mathrm{SI}$ - sem inoculação; $\mathrm{Cl}$ - com inoculação adubação os níveis de inoculação não diferiram estatisticamente mas na dose de $250 \mathrm{~kg} \mathrm{ha}^{-1}$ de adubação a presença do inoculante favoreceu a média do diâmetro da espiga em relação à ausência. Resultados favoráveis foram obtidos por Zucareli et al. (2011) para diâmetro de espigas de milho na presença de Pseudomonas fluorescens.

Os eventos que determinam o diâmetro e o número de fileiras por espiga coincidem com a segunda semana após a emergência das plantas, fase em que se inicia a formação dos primórdios da espiga. Nas condições deste experimento observa-se que na segunda semana após a emergência das plântulas, ocorreram inúmeros registros de precipitação pluviométrica com temperatura média de $20^{\circ} \mathrm{C}$ (Figura 1), beneficiando a interação planta e micro-organismo, tal como o aproveitamento da adubação, o que favoreceu a determinação desses componentes de produção (Figura 1).

Para o peso da espiga não ocorreu, na ausência de inoculação, diferença significativa entre a testemunha e os níveis. A dose de $250 \mathrm{~kg} \mathrm{ha}^{-1}$ de adubação na presença de inoculação foi superior à dose de $125 \mathrm{~kg} \mathrm{ha}^{-1}$. Para efeito de inoculação nas doses de 0 e $125 \mathrm{~kg} \mathrm{ha}^{-1}$ de adubação não houve diferenças significativas mas na dose de $250 \mathrm{~kg} \mathrm{ha}^{-1}$ de adubação a presença de inoculação foi superior à ausência, favorecendo o peso de espiga.

Na Tabela 7 estão os desdobramentos da interação (adubação e inoculação) para massa de 100 grãos e produtividade de grãos. Para a massa de 100 grãos as doses de 0,125 e $250 \mathrm{~kg} \mathrm{ha}^{-1} \mathrm{de}$ adubação não apresentaram diferenças significativas quando na ausência de inoculação. Constatou-se a maior massa de 100 grãos de milho nas plantas adubadas com $250 \mathrm{~kg} \mathrm{ha}^{-1}$ na presença do inoculo, em relação à testemunha.

Andreotti et al. (2008) constataram que a inoculação das sementes com P. fluorescens aumentou a massa de 100 grãos, fato comprovado neste estudo. Gonçalves Júnior et al. (2008) afirmam que as variáveis número de grãos por espiga, massa de 1.000 grãos e produtividade de grãos de milho, apresentaram incrementos quando adubados com NPK. Segundo Amaral Filho et al. (2005) a adubação nitrogenada aumentou linearmente 
Tabela 7. D esdobramento da interação para médias de massa de 100 grãos e produtividade de plantas de milho, em função de diferentes doses de adubação N PK e inoculação das sementes com Pseudomonas fluorescens

\begin{tabular}{cccccc}
\hline $\begin{array}{c}\text { Adubação } \\
\text { (kg ha }^{-1} \text { ) }\end{array}$ & \multicolumn{2}{c}{ Massa $\mathbf{1 0 0}$ grãos (g) } & & \multicolumn{2}{c}{ Produtividade (kg ha ${ }^{-1}$ ) } \\
\cline { 2 - 3 } \cline { 5 - 6 } & $\mathbf{S I}$ & $\mathbf{C l}$ & & $\mathbf{S I}$ & $\mathbf{C l}$ \\
125 & $32,00 \mathrm{Aa}$ & $26,50 \mathrm{Bb}$ & & $2865,53 \mathrm{Aa}$ & $2355,55 \mathrm{Ba}$ \\
250 & $30,00 \mathrm{Aa}$ & $29,25 \mathrm{ABa}$ & & $2809,33 \mathrm{Aa}$ & $2469,26 \mathrm{Aba}$ \\
& $30,00 \mathrm{Aa}$ & $31,25 \mathrm{Aa}$ & & $2673,00 \mathrm{Aa}$ & $3271,20 \mathrm{Aa}$ \\
\hline
\end{tabular}

Médias seguidas de mesma letra maiúscula na coluna para efeito de adubação e minúscula na linha para efeito de inoculação, não diferem entre si pelo teste de Tukey a 0,05 de probabilidade $\mathrm{SI}$ - sem inoculação; $\mathrm{Cl}$ - com inoculação

o número de grãos por espiga e na massa de 1.000 grãos de milho cultivado na primeira safra no sistema de plantio direto.

A produtividade de grãos na presença de inoculante na dose de $250 \mathrm{~kg} \mathrm{ha}^{-1}$ de adubação foi superior à testemunha enquanto na ausência de inoculação não houve diferença significativa para a testemunha e as doses de adubação avaliadas. Para efeito de inoculação nas doses de 0, 125 e 250 $\mathrm{kg} \mathrm{ha}^{-1}$ de adubação não houve diferença significativa para efeito de inoculante. Naveed et al. (2008) obtiveram incrementos na massa de 1.000 grãos e aumento na produtividade de grãos de milho na presença de Pseudomonas fluorescens, associados ao fertilizante orgânico com adição de $88 \mathrm{~kg} \mathrm{ha}^{-1}$ de adubação nitrogenada.

A produtividade média geral de grãos foi de $2.740 \mathrm{~kg} \mathrm{ha}^{-1}$, inferior, portanto, à média para o estado do Paraná que se situa entre 3.000 a $4.000 \mathrm{~kg} \mathrm{ha}^{-1}$ para o milho de segunda safra (CONAB, 2009). Este resultado inferior à média Estadual é consequência da estiagem ocorrida no período compreendido entre final de março até início de maio; além disso, geadas ocorridas no início de junho também afetaram o desenvolvimento das plantas, intensificando a redução da produtividade (Figura 1).

De acordo com Cardoso et al. (2004) os elementos climáticos apresentam grande variabilidade espacial e temporal devido à ocorrência de períodos prolongados de escassez de chuvas e baixas temperaturas no período usual de cultivo do milho de segunda safra, no Paraná. A produção por área pode ficar comprometida se a deficiência hídrica coincidir com o período do florescimento, fase que determina a quantidade de óvulos a serem fecundados e, por consequência, a produção de grãos. Nas três semanas que antecederam o florescimento masculino não houve registros de precipitação pluviométrica (Figura 1) o que, por certo, contribuiu para redução de produtividade.

A disponibilidade hídrica na fase de desenvolvimento da cultura pode ter prejudicado o aproveitamento da adubação mineral visto que o principal mecanismo de contato entre o fósforo e as raízes no solo é a difusão e apenas o P que se encontra próximo às raízes está estrategicamente disponível para ser absorvido. A escassez hídrica tende a prejudicar a absorção do P ocasionando, durante a formação da espiga, redução do seu tamanho, levando a um número menor de grãos por espiga e, em contrapartida, menor produtividade de grãos.

A escassez hídrica a baixa temperatura com registros de geadas, pode ter afetado a sobrevivência, a estabilidade, a multiplicação e a associação das rizobactérias com a cultura, haja vista que referidas rizobactérias podem apresentar comportamento diferenciado, de acordo com a variação climática e o nível de fertilidade do solo, resultando em diferentes respostas do desenvolvimento vegetal.

Considerando o potencial do uso de RPCPs tanto em promover o crescimento quanto em aumentar o rendimento de culturas, insucessos também não são incomuns, como descrevem Freitas \& Aguilar Vildoso (2004), em que o comportamento de Pseudomonas fluorescentes foi instável quanto à promoção do crescimento de plantas cítricas. Um dos obstáculos para a utilização do inoculante à base de Pseudomons, é a dificuldade das bactérias se estabelecerem e sobreviver em condições de campo (Atkinson \& Watson, 2000). Assim, seria importante avaliar a dinâmica desses microorganismos no solo, de forma a complementar as avaliações de desenvolvimento e o desempenho produtivo das plantas.

As condições climáticas inadequadas à cultura do milho e que predominaram durante o período de condução do experimento refletiram, possivelmente na produtividade de grãos e, sem dúvida, minimizaram os efeitos benéficos tanto da adubação quanto da inoculação com $P$. fluorescens. Nas condições adequadas de clima é provável que os efeitos dos fatores estudados sejam mais expressivos, favorecendo ainda mais o potencial produtivo da cultura. Portanto, torna-se imprescindível dar continuidade a estudos similares a este em condições de campo, com diferentes cultivares e períodos de instalação da cultura para obtenção de resultados mais consistentes com a lavoura de milho, seja em cultivo de primeira seja de segunda safra.

\section{CONClusão}

A inoculação com Pseudomonas fluorescens associada à adubação de semeadura com $250 \mathrm{~kg} \mathrm{ha}^{-1}$ de NPK, favorece o desenvolvimento e o desempenho produtivo do milho de segunda safra.

\section{LITERATURA CITADA}

Afzal, A.; Bano, A. Rhizobium and phosphate solubilizing bactéria improve the yild and phosphorus uptake in wheat (Triticum aestivum). International Journal of Biology, v.10, p.85-88, 2008.

Almeida, M. L.; Merotto Júnior, A.; Sangoi, L.; Ender, M.; Guidolin, A. F. Incremento na densidade de plantas: uma alternativa para aumentar o rendimento de grãos de milho em regiões de curta estação estival de crescimento. Ciência Rural, v.30, p.23-29, 2000.

Amaral Filho, J. P. R.; Fornasieri Filho, D.; Farinelli, R.; Barbosa, J.R. Espaçamento, densidade populacional e adubação nitrogenada na cultura do milho. Revista Brasileira de Ciência do Solo, v.29, p.467-473, 2005.

Andreotti, M.; Lodo, B. N.; Basso, F. C.; Pariz, C. M.; Buzetti, S. Avaliação da eficência agronômica do inoculante Rizofós contendo Pseudomonas fluorescens em cultivo de milho safrinha. In: Reunião Brasileira de Fertilidade do Solo e Nutrição de Plantas, 28, 2010, Londrina. Anais...Londrina: SBCS, 2008. CD Rom. 
Aratani, R. G.; Fernandes, F. M.; Mello, L. M. M. de. Adubação nitrogenada de cobertura na cultura do milho irrigado, em sistema plantio direto. Revista Científica Eletrônica de Agronomia, v.5, p.1-10, 2006.

Atkinson, D.C.; Watson, A. The beneficial rhizosphere: A dynamic entity. Applied Soil Ecology, v.15, p.99-104, 2000.

Cardoso, C. O.; Faria, R. T.; Folegatti, M. V. Simulação do rendimento e riscos climáticos para o milho safrinha em Londrina - PR, utilizando o modelo CERES-Maize. Engenharia Agrícola, v.24, p.291-300, 2004.

Cardoso, I. C. M.; Mariotto, J. R.; Klauberg Filho, O.; Santos, J. C. P.; Felipe, A. F.; Neves, A.N.; Miquelutti, D. J. Resposta de milho (Zea mays L.) precoce à inoculação de rizobactérias em casa-de-vegetação. In: Reunião Brasileira de Fertilidade do Solo e Nutrição de Plantas, 28, 2008, Londrina. Anais...Londrina: SBCS, 2008. CD Rom.

Coelho, L. F.; Freitas, S. S.; Melo, A. M. T.; Ambrosano, G. M. B. Interação de bactérias fluorescentes do gênero Pseudomonas e de Bacillus spp. com a rizosfera de diferentes plantas. Revista Brasileira de Ciência do Solo, v.31, p.1413-1420, 2007.

CONAB - Companhia Nacional de Abastecimento. Acompanhamento da safra Brasileira: Grãos: Décimo segundo levantamento, setembro 2009. Brasília: CONAB, 2009. 43p.

Deparis, G. A.; Lana, M. do C.; Frandoloso, J. F. Espaçamento e adubação nitrogenada e potássica em cobertura na cultura do milho. Acta Scitiarum Agronomy, v.29, p.517-525, 2007.

EMBRAPA - Empresa Brasileira de Pesquisa Agropecuária. Centro Nacional de Pesquisa de Solos. Sistema brasileiro de classificação de solos. Rio de Janeiro: Embrapa Solos, 1999. 412p.

EMBRAPA - Empresa Brasileira de Pesquisa Agropecuária. Nutriçãoe adubação do milho. <http://www.cnpms.embrapa.br/ publicacoes/milho/feraduba.htm>. 15 Fev. 2009.

Freitas, S.; Aguilar Vildoso, C. I. Rizobactérias e promoção do crescimento de plantas cítricas. Revista Brasileira de Ciência do Solo, v.28, p.987-994, 2004.

Gonçalves Júnior, A. C.; Nacke, H.; Strey, L.; Schwantes, D.; Selzlein, C. Produtividade e componentes de produção do milho adubado com $\mathrm{Cu}$ e NPK em um argissolo. Scientia Agrária, Curitiba, v.9, p.35-40, 2008.

Gonçalves Júnior, A. C.; Trautmann, R. R.; Marengoni, N. G.; Ribeiro, O. L.; Santos, A. L. Produtividade do milho em resposta a adubação com NPK e Zn em Argissolo Vermelhoamarelo Eutrófico e Latossolo Vermelho Eutroférrico. Ciência e Agrotecnologia, v.31, p.1231-1236, 2007.
Harger, N.; Brito, O. R.; Ralisch, R.; Ortiz, F. R.; Watanabe, T. S.Avaliação de fontes e doses de fósforo no crescimento inicial do milho. Semina. Ciências Agrárias, v.28, p.39-44, 2007.

Lifishitz, R.; Kloepper, Q. Q.; Kazlowski, M.; Simonson, C.; Carlson, J. Tipping, E.; Zaleska, I. Growth promoting of canola (rapessed) sedlig by strian of Pseudomonas putida under gnobiotic conditions. Canadian Journal of Microbiology, v.33, p.390-395, 1987.

Naveed, M.; Khalid, M.; Jones, D.L.; Ahmad, R.; Zahir, Z.A. Relative efficacy of pseudomonas spp., containing accdeaminase for improving growth and yield of maize (zea mays L.) in the presence of organic fertilizer. Pakistan Journal of Botany, v.40, p.1243-1251, 2008.

Oliveira Júnior, A. de; Prochnow, L. I.; Klepker, D. Eficiência agronômica do fosfato natural reativo na cultura da soja. Pesquisa Agropecuária Brasileira, v.43, p.623-631, 2008.

Raij, B. van .; Quaggio, A. J. Métodos de análise de solo para fins de fertilidade. Campinas: Instituto Agronômico, 1983. $31 p$.

Rana, A.; Joshi, M.; Prasanna, R.; Shivay, Y.S.; Nain, L. Biofortification of wheat through inoculation of plant growth promoting rhizobacteria and cyanobacteria. European Journal of Soil Biology, v.50, p.118-126, 2012.

Richardson, A. E. Prospects for using soil microrganisms to improve the acquisition of phosphorus by plants. Australian Journal of Plant Physiology, v.28, p.897-906, 2000.

Ritchie, S. W.; Hanway, J. J.; Benson, G. O. How a Corn Plant Develops. Special Report no 48, Ames: Iowa State University of Science and Technology, 1986.21p. Special Repórter, 48

Rodríguez, H.; Fraga, R. Phosphate solubilizing bacteria and their role in plant growth promotion. Biotechnology Advances, v.17, p.319-339, 1999.

Sheng, X.F.; He, L.Y. Solubilization of potassium-bearing minerals by a wildtype strain of Bacillus edaphicus and its mutants and increased potassium uptake by wheat. Canadian Journal Microbiology, v.52, p.66-72, 2006.

Zaidi, A.; Mohammad, S. Co-inoculation effects of phosphate solubilizing microorganisms and glomus fasciculatum on green gram-bradyrhizobium symbiosis. Turkish Journal of Agriculture and Forestry, v.30, p.223-230, 2006.

Zucareli, C.; Cil, I.R.; Prete, C. E. C.; Prando, A. M. Eficiência agronômica da inoculação à base de Pseudomonas fluorescens na cultura do milho. Revista Agrarian, v.4, p.152$157,2011$. 